\title{
High doses of medroxyprogesterone as the cause of disappearance of adherence of the zona pellucida to an oocyte
}

\author{
Barbara Jodłowska-Jẹdrych • Marian Jẹdrych • \\ Wlodzimierz Matysiak
}

Received: 23 February 2010 / Accepted: 30 July 2010/Published online: 17 August 2010

(C) The Author(s) 2010. This article is published with open access at Springerlink.com

\begin{abstract}
The zona pellucida (ZP) is an external glycoprotein membrane of oocytes of mammals and embryos in the early stage of their development. ZP first appears in growing ovarian follicles as an extracellular substance between the oocyte and granular cells. The zona pellucid markedly affects the development and maturation of the oocyte. The morphology of the ZP-oocyte complex allows a more precise determination of the oocyte maturity. According to numerous experimental studies, ZP is essential for preimplantation embryonic development of humans and other mammals. It prevents dispersion of blastomeres and enhances their mutual interactions. ZP is a dynamic structure responsible for the provision of nutrients to early forms of oocytes in mammals. The aim of the present study was untrastructural evaluation of the ZP-oocyte contact during inhibited ovulation. Female white rats (Wistar strain) received a suspension of medroxyprogesterone acetate (MPA) in incremental intramuscular bolus doses of $3.7 \mathrm{mg}$ (therapeutic dose), $7.4 \mathrm{mg}$ and $11.1 \mathrm{mg}$. The animals were decapitated 5 days after the administration of MPA. Ovarian sections were evaluated under a transmission electron microscope (TEM) Zeiss EM 900. Morphometric analysis of ZP was conducted using the cell imaging system by Olympus. In females exposed to
\end{abstract}

B. Jodłowska-Jędrych $(\bowtie) \cdot$ W. Matysiak

Department of Histology and Embryology,

Medical University of Lublin,

Radziwiłłowska 11,

20-080 Lublin, Poland

e-mail: b.jedrych@gmail.com

M. Jędrych

Department of Mathematics and Biostatistics,

Medical University of Lublin,

Jaczewskiego 4,

20-067 Lublin, Poland therapeutic doses of MPA, ZP showed the structure of granular-fibrous reticulum of a medium electron density with single cytoplasmic processes originating from the surrounding structures. The oocyte cell membrane generated single, delicate processes directed toward ZP. Microvilli of the oocyte were short and thin. In the group receiving $7.4 \mathrm{mg}$ of MPA, ZP had the structure of a delicate, loose granular-fibrous reticulum, and the oocyte cell membrane generated single microvilli directed toward ZP. In both those groups, the close ZP-oocyte contact was observed. Otherwise, in the group exposed to the highest MPA doses $(11.1 \mathrm{mg})$, thicker and more numerous oocyte microvilli were found, which did not penetrate ZP matrix. They were dense, irregularly separated contour, forming a barrier between $\mathrm{ZP}$ and oocyte. The present findings are likely to suggest that MPA has inhibiting effects on the synthesis of binding proteins and causes the loss of the oocyte contact with ZP.

Keywords Zona pellucida - Oocyte .

Medroxyprogesterone · Transmission electron microscopy

\author{
Abbreviations \\ ZP Zona pellucida \\ MPA Medroxyprogesterone acetate \\ O Oocyte
}

\section{Introduction}

The zona pellucida (ZP) is an external glycoprotein membrane of oocytes of mammals and embryos in the early stage of development (Dunbar et al. 2001; Prasad et 
al. 2000; Sinowatz et al. 2001a, b; Zhao and Dean 2002). ZP first appears in growing ovarian follicles as an extracellular substance between the oocyte and granule cells (Rankin et al. 2000).

Ultrastructural studies in mouse oocytes from primary follicles reveal the presence of electron-dense matrix filling the depressions among oocyte microvilli (Zhao and Dean 2002). Such a matrix is considered to be the first element of the developing ZP. The ovarian follicle growth coincides with changes in the structure and thickness of ZP (Qi et al. 2002; Vanroose et al. 2000).

The site of ZP biosynthesis has not been entirely explained. According to some authors, ZP is synthesized by the oocyte (Epifano et al. 1995; Haddad and Nagai 1977; Kimura et al. 1994). Observations of mouse oocytes conducted by Wassarman et al. (2004) suggest a considerable involvement of the oocyte Golgi apparatus in modifying protein particles, which are the precursors of ZP glycoproteins. The highest activity of this cell organelle was observed in gametes located in growing ovarian follicles. A large number of secretory follicles were found in the circumferential part of the cytoplasm. The studies mentioned suggest that the synthesis of ZP takes place inside the oocyte. Moreover, as shown by the findings of other studies in mice, the oocyte is the sole element responsible for the synthesis of this structure (Epifano et al. 1995; Haddad and Nagai 1977; Kimura et al. 1994).

However, the majority of authors provide evidence that the zone pellucida is created by both the oocyte and granule cells, with greater impact on the latter (Bogner et al. 2004; Rankin et al. 2000; Sinowatz et al. 2001a, b).

$\mathrm{ZP}$ has a fibrous structure. It consists of the complex of four glycoproteins, designated as ZP1, ZP2, ZP3 and ZP4. The active synthesis of $Z \mathrm{P}$ proteins decreases at the end of oogenesis, and de novo synthesis is infeasible after implantation (Bleil and Wassarman 1980; Shimizu et al. 1983).

Glycoproteins determine the specific structure of the surface of the external ZP, which is not uniform. Visualization of canine oocytes by scanning electron microscopy has shown that ZP has a structure of fibrous network with the presence of a varying number of fenestrations (Ström Holst et al. 2000). Moreover, according to Strőm Holst et al. (2000), there are no morphological differences in the envelope depending on the oocyte age.

Analyzing the surface structure of ZP of human oocytes, Magerkurth et al. (1999) divided ZPs into several types, i.e., type $\mathrm{A}$ - the surface of $\mathrm{ZP}$ has the form of a network with numerous pores and depressions; type $\mathrm{B}-\mathrm{a}$ similar structure, yet the depressions are shallower and smaller in diameter compared to class A; type $\mathrm{C}-\mathrm{a}$ spongy, uneven surface, very few or even no pores: the network structure almost disappears and type D-characterized by an almost smooth external surface: traces of pores and depressions visible only in some places.

ZP constituting the natural surrounding provides the oocyte with natural microenvironment and has an important influence on its development and maturation. ZP and granule cells forming the corona radiata are responsible for the biological functions of the gamete. The morphology of the ZP-oocyte complex allows a more precise determination of the oocyte maturity.

Many of the published experimental studies confirm the crucial role played by ZP during the preimplantation embryonic development of man and other mammals (Bauskin et al. 1999; Parillo et al. 2005; Wassarman et al. 2004; Zhao and Dean 2002). ZP is an integral part of the embryo in the normal course of an early period of development (Jelinkova et al. 2003). It prevents the dispersion of blastomeres, created in the process of blastulation, and enhances their mutual interactions.

As a dynamic structure, ZP is responsible for the delivery of nutritional components to the early form of a fetal ovum in mammals (Wassarman et al. 2001; Zhao and Dean 2002).

The thickness of ZP varies. In man, it ranges from 13 to $16 \mu \mathrm{m}$ (Dunbar and Wolgemuth 1984) or from 15 to $18 \mu \mathrm{m}$ (Rankin et al. 1996). In mice, ZP is $7 \mu \mathrm{m}$ thick (Florman et al. 1984).

In the studies on extracorporeal fertilization of human oocytes, Bertrand et al. (1995) have demonstrated that the thickness of $\mathrm{ZP}$ is different both in fertilized and in nonfertilized oocytes. ZP thickness was significantly smaller in fertilized oocytes in which the mean value was $16.6 \mu \mathrm{m}$, whereas in non-fertilized oocytes, it was $18.9 \mu \mathrm{m}$. The authors suggest that with ZP thickness of $22 \mu \mathrm{m}$ or more the chances of fertilization are considerably lower.

The attempts to reduce ZP thickness using laser radiation have shown no influence of such changes on fertilization, blastulation, implantation or early abortions (Petersen et al. 2002). The results were similar to the observations made in groups of animals whose oocytes were not exposed to laser radiation.

The experimental studies in dogs, cats, horses and elephants prove that an increase in the diameter of the ovarian follicle significantly coincides with an increase in the thickness of ZP (Barber et al. 2001).

A decrease in $Z P$ thickness before implantation depends on its mechanical stretching resulting from subsequent stages of embryonic development (Confino et al. 1997). The theory of ZP mechanical stretching assumes its centrifugal "thinning" caused by the growth of the embryo. According to the authors, a change in ZP thickness may be caused by an enzymatic effect of the trophoblast or the specific environment of the uterine tube and uterus. The smallest thickness of $\mathrm{ZP}$ occurs shortly before implantation at the site where ZP 
will disrupt, i.e., in the area of the blastocyst pole, which is implanted into the mucosa of the uterus.

$\mathrm{ZP}$ is an indispensable element of the fertilization process. It performs three fundamental functions: it binds a spermatozoon - thus preventing interspecies fertilization; it induces the acrosome reaction of the spermatozoon; and, finally, immediately after fertilization, it prevents polyspermy (Baker et al. 2000; Bleil and Wassarman 1990; Herrler and Beier 1999; Serrano and Garcia-Suarez 2001; Thaler and Cardullo 2002; Yanagimachi 1994; Zhao and Dean 2002).

It seems that the adherence of ZP to the oocyte is necessary for a proper function of the oocyte. The oocyte sending cytoplasmic processes into ZP ensures transmission of signals to the environment as well as their reception.

Stanger et al. (2001) questioned the role of ZP as an indispensable early embryonic element. In the studies on in vitro fertilization in man, it was observed that the oocytes from induced cycles had thin or no ZP, which demonstrated that the environment provided was insufficient for the development of blastomeres and the embryo. Finally, the percentage of successful implantations was as low as 0.7 .

Similar opinions were presented by Zhao and Dean (2002). In their experimental studies in mice, the authors found that the development of oocytes, with a structurally defective or missing ZP progressed through subsequent stages of folliculogenesis and then isolated only few/single oocytes, could be fertilized in vitro. The defect in ZP matrix significantly affected the decrease in the number of mature follicles and reduced the follicle lifetime period.

For therapeutic purposes aimed at stimulation of ovulation, some other methods are also used, which pharmacologically inhibit maturation of ovaries and thus inhibit ovulation. In order to inhibit ovulation, synthetic derivatives of progesterone are used. To achieve a prolonged action, medroxyprogesterone acetate (MPA) is applied. MPA has strong progestagenic and antigonadotrophic effects. The chemical compound is a derivative of $17 \alpha$-hydroxyprogesterone and shows high affinity for progesterone receptors. The prolonged action of the steroid is a result of slow absorption from the site of injection. After intramuscular administration, it inhibits the secretion of pituitary gonadotrophins, which in turn makes the maturation of ovarian follicles impossible in women at reproductive age. It inhibits luteinizing hormone $(\mathrm{LH})$ release, occurring in the middle of the cycle, thus halting ovulation. MPA slightly decreases follicle-stimulating hormone (FSH) concentrations and, consequently, does not inhibit the growth of ovarian follicles. MPA does not show estrogenic activity, and its androgenic action is almost lacking. Twenty-four hours after intramuscular administration of a single dose of
MPA, ovulation is inhibited; the maximum concentration is achieved after approx. 4 to 20 days.

The morphology of the ZP-oocyte complex allows a more accurate determination of the oocyte maturity. Studying the fine structure of this complex in the state of inhibited ovulation after administration of MPA should provide an additional morphological criterion, which may increase our current knowledge on implantation effectiveness of the oocyte. The aim of the study was ultrastructural evaluation of the ZP contact with the oocyte after the administration of MPA.

\section{Material and methods}

Twenty mature female white rats of Wistar strain (age range 2.5-3.0 months, body weight $250-300 \mathrm{~g}$ ) were studied. Animals were housed in metal cages with a light regime of $14 \mathrm{~h} \mathrm{light} / 8 \mathrm{~h}$ dark and room temperature of 21 to $23^{\circ} \mathrm{C}$. Rats were fed on a standard diet and had free access to water. Effects of stress were reduced to a minimum. Animals were randomly divided into three experimental groups (D1-D3) and one control group (C).

The study design was approved by the Ethical Committee of the Medical University of Lublin.

The day of the estrus cycle was determined by vaginal swabs (9 a.m., each morning) according to the Freeman method (Freeman 1994).

MPA was administered in three incremental doses. Animals received the suspension of MPA (Pharmacia NV/ SA, Belgium).

The animals were divided into three experimental groups, with 5 rats each, as follows:

- D1-a single dose of $3.7 \mathrm{mg}$ (therapeutic dose) per $300 \mathrm{~g}$ body weight

- D2 - a single dose of $7.4 \mathrm{mg}$

- D3-a single dose of $11.1 \mathrm{mg}$

Experimental animals were decapitated 5 days after administration of MPA. Control animals received an intramuscular injection of $0.1 \mathrm{ml}$ of saline $(0.9 \%$ sodium chloride) per 100 gram body weight and were decapitated $14 \mathrm{~h}$ after saline injections.

\section{Ultrastructural examinations}

The samples for TEM examinations was prepared as follows: first, they were fixed in $4 \%$ glutaraldehyde for $4 \mathrm{~h}$ and rinsed in cacodylate buffer for $12 \mathrm{~h}$; and then fixed in $2 \%$ osmium tetroxide $\left(\mathrm{OsO}_{4}\right)$ for $1 \mathrm{~h}$ and rinsed in distilled water for $2 \mathrm{~min}$. Next, the specimens were dehydrated in a series of alcohols with increasing concentrations: $30 \%, 50 \%, 70 \%, 90 \%$, and $100 \%$. The tissue 
fragments were placed in a solution of propylene oxide and embedded in epoxy resin Epon 812 (MNA, DDSA, DNP-30) according the following schedule:

- propylene oxide + resin $(2: 1)$ for $1 \mathrm{~h}$

- propylene oxide + resin $(1: 1)$ for $1 \mathrm{~h}$

- propylene oxide + resin $(1: 2)$ for $1 \mathrm{~h}$

The resin and tissue fragments were placed in gelatinous capsules and polymerized at the temperature of $60^{\circ} \mathrm{C}$ for $24 \mathrm{~h}$. The blocks were slices using the RMC MT-7 ultramicrotome cutter (USA). Semithin slices $(1 \mu \mathrm{m})$ were stained with methylene blue; preliminary selection of ovarian follicles was performed using light microscopy.

Ultrathin slices $(80 \mathrm{~nm})$ were stained with Reynolds liquid (lead nitrate + sodium citrate; Reynolds 1963). Ultrastructural evaluation and photographic documentation were performed using TEM Zeiss EM 900. Evaluation involved only mature cavitary ovarian follicles.

\section{Morphometry}

The thickness of $\mathrm{ZP}$ was measured in methylene bluestained semithin sections $(1 \mu \mathrm{m})$ at $200 \times$ using the cell imaging system by Olympus version A, eight measurements of ten semithin sections of each ZP.

\section{Statistics}

In each group, the maximum, the arithmetic mean \pm standard deviation (SD) and standard error (SE) were calculated. To test for significant intergroup differences $(p<0.05)$, the Kruskal-Wallis one-way analysis of variance by ranks and multivariate analysis were applied (Brandt 1998). The calculations were made using STATISTICA 8.0 software.

\section{Results}

\section{Electron microscope}

ZP of animals in group D1 revealed a granular-fibrous network with a medium electron density. Single cytoplasmic processes coming from the surrounding structures were found within ZP. Oocyte membranes produced single, delicate processes directed toward ZP (Fig. 1). The oocyte microvilli were short and thin. Ultrastructural analysis disclosed a close contact between the analyzed structures. In group D2, the ZP structure (Fig. 2) was similar to that in group D1, yet cytoplasmic processes inside the ZP network were more numerous compared to group D1. Oocyte microvilli were short and thin, but cytoplasmic processes of granule cells were considerably thicker.

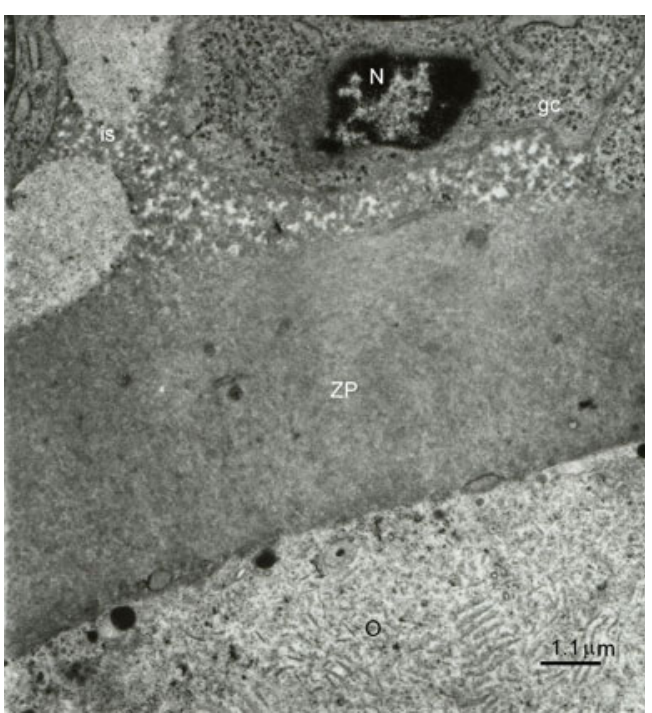

Fig. 1 Fine structure of contact between the zona pellucida $(Z P)$ and oocyte $(O)$. Group D1 (3.7 mg MPA). Note the granule cells $(g c)$ of the corona radiata adjoining $\mathrm{ZP}$. $N$ Nucleus of gc, is intercellular space

In group D3, oocyte microvilli were more numerous, thicker and did not penetrate the matrix of ZP (Fig. 3). Only single-oocyte cytoplasmic processes extended toward ZP. Fine structure was observed in the majority of ovarian follicles in this group. ZP had the structure of a delicate, loose granular-fibrous network with lower electron density compared to the previous groups.

Measurements of ZP thickness showed significant differences $(F=291.219, p<0.001)$ between the experimental groups, with the lowest thickness of $2.28 \mu \mathrm{m}$ in group D1 and the largest thickness of $10.767 \mu \mathrm{m}$ in group D3 (Table 1). The lowest mean thickness of ZP was found in group D2;

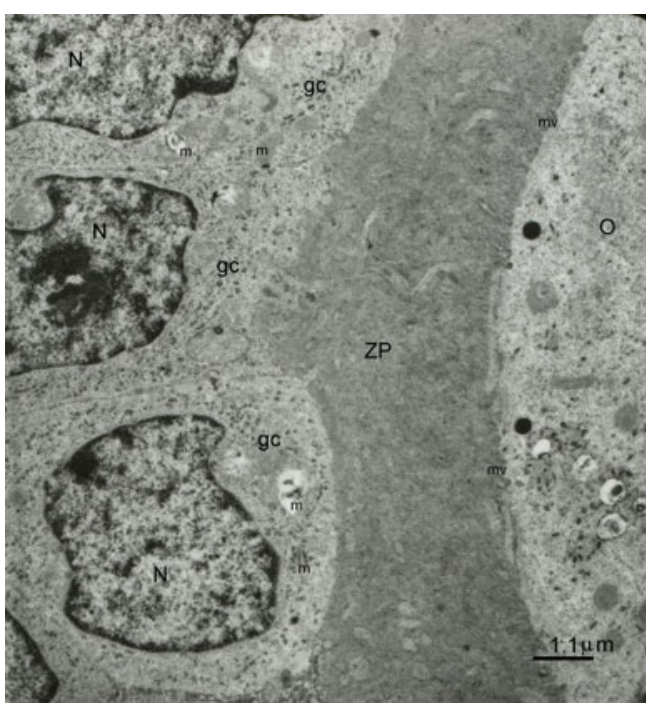

Fig. 2 Fine structure of contact between the zona pellucida $(Z P)$ and oocyte $(O)$. Group D2 (7.4 mg MPA). Note the short, thin microvilli $(m v)$ of the oocyte $(O)$ 


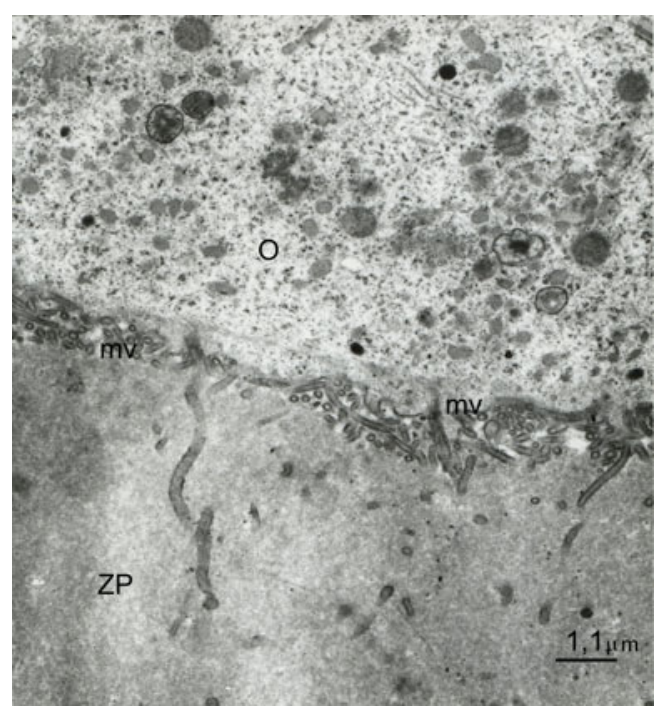

Fig. 3 Fine structure of contact between the zona pellucida $(Z P)$ and oocyte $(O)$. Group D3 (11.2 mg MPA). Abundant microvilli $(m v)$ of the oocyte $(O)$ facing the zona pellucida $(Z P)$, yet not penetrating ZP3

the highest $(8.369 \mu \mathrm{m})$ was found in group D3 $(11.2 \mathrm{mg}$ MPA), i.e., in the group of rats receiving MPA in the highest dose. The greatest variation in ZP thickness was observed in group D1 (3.7 mg MPA, the therapeutic dose; Table 1).

Comparison of ZP thickness between the experimental groups revealed that $\mathrm{ZP}$ thickness was significantly lower in group D1 and group D2 compared to group D3, which did not show differences in comparison with group $\mathrm{C}$ (Table 2). ZP thickness was found to be significantly smaller in the ovarian follicles of female rats in groups D1 and D2. ZP thickness in group D3, however, did not reveal significant differences compared to controls, group C.

\section{Discussion}

In recent years, an increasing number of studies have been conducted on morphology of the ovarian follicles, largely expanding the available knowledge about the dynamics of the development of oocytes and adjacent structures.

The oocyte, ZP and granule cells of the corona radiata are considered to be the measurement tools for reproduction capacity of mammals. Changes in the composition of the
Table 2 Comparison of zona pellucida thickness in experimental and control groups

\begin{tabular}{|c|c|c|c|c|}
\hline \multirow{2}{*}{\multicolumn{2}{|c|}{$p$ Value }} & \multirow[b]{2}{*}{0.000} & \multirow[b]{2}{*}{0.000} & \multirow[b]{2}{*}{0.000} \\
\hline & & & & \\
\hline D2 & 0.000 & & 0.000 & 0.000 \\
\hline D3 & 0.000 & 0.000 & & 0.310 \\
\hline $\mathrm{C}$ & 0.000 & 0.000 & 0.310 & \\
\hline
\end{tabular}

Approximate values. A $p$ value of 0.000 means that the significance level $p<0.0005$

structures in question are likely to cause failures in fertilization or embryo development as well as lack of egg implantation.

The results of the present study indicate that both stimulation and inhibition of ovulation induce changes in the examined structures, ZP and corona radiata cells. ZP is a structure sensitive to the effect of substances that inhibit ovulation.

While evaluating the site of ZP and oocyte contact, no microvilli or only single microvilli directed toward ZP were observed. Their number increased together with an increase in MPA doses, yet these were only single cytoplasmic processes. The oocyte membrane generated single microvilli in the direction of $\mathrm{ZP}$. In group D3 receiving the highest dose of MPA, there were sites where the oocyte microvilli did not penetrate the ZP matrix, forming a barrier between ZP and oocyte.

The available literature does not provide much information about the effect of ovulation inhibitors on the ultrastructure of the ZP-oocyte contact. Different observations were reported by Durlinger et al. (2000), who studied the effect of the GnRH antagonist on rat ovaries. The administered substance had inhibiting effects on ovulation, and the microscopic images of ovaries were dominated by granule cells with pycnotic nuclei. Moreover, the changes were present in the oocyte, cumulus oophorus and follicle antrum, yet no changes were observed in ZP. All the changes were progressive and intensified with the duration of observation of the ovarian follicles. Therefore, all the above observations strongly suggest that MPA is responsible for such an ultrastructural image of ZP. MPA makes the maturation of ovarian follicles impossible, but it inhibits their growth only to a certain extent. The ultrastructural

Table 1 Zona pellucida thickness in experimental and control groups (in $\mu \mathrm{m}$ )

\begin{tabular}{lllllll}
\hline Group & Mean $(\mathrm{M})$ & Number & Standard deviation (SD) & Standard error (SE) & Minimum & Maximum \\
\hline D1 & 4.448 & 60 & 1.341 & 0.173 & 3.000 & 7.500 \\
D2 & 3.068 & 55 & 0.456 & 0.062 & 2.280 & 4.250 \\
D3 & 8.369 & 25 & 1.032 & 0.206 & 6.965 & 10.767 \\
C & 8.155 & 40 & 0.642 & & 0.101 & 7.150 \\
\multicolumn{2}{l}{ Variance analysis } & & $F=291.219 ; p<0.001$ & & 10.500 \\
\hline
\end{tabular}


studies revealed the granular-fibrous structure of ZP. The ZP matrix showed medium electron density; it is only in group D3 that the density was lower than that in the other groups. The molecular composition of $\mathrm{ZP}$ is characteristic of mammals, humans and rats included. Wassarman et al. (2004) studying ZP in mice showed that the ZP external layer had higher electron density compared to the internal layer adjacent to the oocyte. In our material, such a polar differentiation of electron density in ZP was not observed.

The results of ZP thickness measurements varied greatly. The greatest variation was observed in group D1. In group $\mathrm{D} 2$, the smallest thickness of $2.280 \mu \mathrm{m}$ was found compared to the remaining experimental groups. ZP thickness values in group D3 were significantly higher than those in the control group.

Many factors are considered to affect the structure and thickness of ZP. If the granule cells are involved in the synthesis of ZP glycoproteins, then what mechanism is responsible for such a large differentiation of ZP thickness in experimental groups? It should be stressed that the smallest ultrastructural changes were observed in the groups exposed to MPA. The administered MPA may have inhibited the transcription processes in the granule cells.

Biological effects of MPA are caused by MPA itself, its metabolites and FSH. The findings imply that MPA has an inhibiting effect on the synthesis of binding proteins, thus leading to the loss of the oocyte-ZP contact. In addition, injection of $11.2 \mathrm{mg}$ MPA does not impair the synthesis of $\mathrm{ZP}$ glycoproteins, as the ZP thickness was similar to that in control animals.

Conflict of interest The authors declare that they have no conflict of interest.

Open Access This article is distributed under the terms of the Creative Commons Attribution Noncommercial License which permits any noncommercial use, distribution, and reproduction in any medium, provided the original author(s) and source are credited.

\section{References}

Baker HG, Liu DY, Garret C, Martic M (2000) The human acrosome reaction. Asian J Androl 2:172-178

Barber MR, Lee SM, Steffens WL, Ard M, Fayrer-Hasken RA (2001) Immunolocalization of zona pellucida antigens in the ovarian follicle of dogs, cats, horses and elephants. Theriogenology 55:1705-1717

Bauskin AR, Franken DR, Eberspaecher U, Donner P (1999) Characterization of human zona pellucida glycoproteins. Mol Hum Reprod 5:534-540

Bertrand E, Van Den Bergh M, Englert Y (1995) Does zona pellucida thickness influence the fertilization rate? Hum Reprod 10:1189-1193

Bleil JD, Wassarman PM (1980) Structure and function of the zona pellucida: identification and characterization of the proteins of the mouse oocyte's zona pellucida. Dev Biol 76:185-202
Bleil JD, Wassarman PM (1990) Identification of a ZP3-binding protein on acrosome - intact mouse sperm by photoaffinity crosslinking. Proc Natl Acad Sci USA 87:5563-5567

Bogner K, Hinsch KD, Nayudu P, Konrad L, Cassara C, Hinsch E (2004) Localisation and synthesis of zona pellucida proteins in the marmoset monkey (Callithrix jacchus) ovary. Mol Hum Reprod 10:481-488

Brandt S (1998) Analiza danych. Metody statystyczne i obliczeniowe. Wydawnictwa Naukowe PWN, Warszawa

Confino E, Rawlins R, Binor Z, Radwańska E (1997) The effect of the oviduct, uterine, and in vitro environments on zona thinning in the mouse embryo. Fertil Steril 68:164-167

Dunbar BS, Wolgemuth DJ (1984) Structure and function of the mammalian zona pellucida, a unique extracellular matrix. Mod Cell Biol 3:77-111

Dunbar BS, Timmons TM, Skinner SM, Prasad SV (2001) Molecular analysis of a carbohydrate antigen involved in the structure and function of zona pellucida glycoproteins. Biol Reprod 65:951960

Durlinger AL, Kramer P, Karels B, Grootegoed JA, Uilenbrock JThJ, Themmen AP (2000) Apoptotic and proliferative changes during induced atresia of pre-ovulatory follicles in the rat. Hum Reprod $15: 2504-2511$

Epifano O, Liang LF, Familari M, Moos MC Jr, Dean J (1995) Coordinate expression of the three zona pellucida genes during mouse oogenesis. Development 121:1947-1956

Florman HM, Bechtol KB, Wassarman PM (1984) Enzymatic dissection on the functions of the mouse egg's receptor for sperm. Dev Biol 106:243-255

Freeman, ME (1994) The neuroendocrine control of the ovarian cycle of the rat. In: Knobil E, Neill JD, Greenwald GS, Markert CL, and Pfaff DW (eds) The physiology of reproduction. Raven Press, New York, N.Y., pp 613-658

Haddad A, Nagai ME (1977) Radioautographic study of glycoprotein biosynthesis and renewal in the ovarian follicles of mice and the origin of the zona pellucida. Cell Tissue Res 177:347-369

Herrler A, Beier HM (1999) Reproductionsmedizin, vol 15. Springer, pp 268-275

Jelinkova L, Pavełkova J, Streher E, Paulus W, Zivny J, Sterzik K (2003) Improved implantation rate after chemical removal of the zona pellucida. Fertil Steril 79:1299-1303

Kimura J, Sato K, Okano M, Tsukise A (1994) Localization of ZP3 mRNA in Mouse ovary by non-radioactive in situ hybridization with digoxigenin-labelled cDNA. Cell Mol Biol 40:10971101

Magerkurth C, Topfer-Petersen E, Schwartz P, Michelmann HW (1999) Scanning electron microscopy analysis of the human zona pellucida: influence of maturity and fertilization on morphology and sperm binding pattern. Hum Reprod 14:1057-1066

Parillo F, Zelli R, Verini Supplizi A, Fagioli O, Gargiulo AM (2005) Topographical localisation of glucidic residues and their variations in the canine zona pellucida during folliculogenesis. J Mol Hist 36:131-137

Petersen CG, Mauri AL, Baruffi RL, Pontes A, Franco JG Jr (2002) Zona thinning with a noncontact diode laser in ICSI embryos from women of advanced age. J Assist Reprod Genet 19:11-512

Prasad SV, Skinner SM, Carino C et al (2000) Structure and function of the proteins of the mammalian zona pellucida. Cells Tissues Organs 166:148-164

Qi H, Williams Z, Wassarman PM (2002) Secretion and assembly of zona pellucida glycoproteins by growing mouse oocytes microinjected with epitope-tagged cDNAs for mZP2 and mZP3. Mol Biol Cell 13:530-541

Rankin T, Familari M, Lee E et al (1996) Mice homozygous for an insertional mutation in the ZP3 gene lack a zona pellucida and are interfile. Development 122:2903-2910 
Rankin T, Soyal S, Dean J (2000) The mouse zona pellucida, folliculogenesis, fertility and pre-implantation development. Mol Cell Endocrinol 163:21-25

Reynolds SS (1963) The use of lead citrate of high ph as an electronopaque stain in electron microscopy. J Cell Biol 17:208 212. doi:10.1083/jeb.17.1.208

Serrano H, Garcia-Suarez D (2001) Molecular aspects of mammalian fertilization. Asian J Androl 3:243-249

Shimizu S, Tsuji M, Dean J (1983) In vitro biosynthesis of three sulfated glycoproteins of murine zonae pellucidae by oocytes grown in follicle culture. J Biol Chem 258:5858-5863

Sinowatz F, Kölle S, Töpfer-Petersen E (2001a) Biosynthesis and expression of zona pellucida glycoproteins in mammals. Cells Tissues Organs 168:24-35

Sinowatz F, Topfer-Petersen E, Kolle S, Palma G (2001b) Functional morphology of the zona pellucida. Anat Histol Embryol 30:257-263

Stanger JD, Stevenson K, Lakmaker A, Woolcott R (2001) Pregnancy following fertilization of zona-free, coronal cell intact human ova: case report. Hum Reprod 16:164-167
Strőm Holst B, Larsson B, Linde-Forsberg C, Rodriquez-Martinez $H$ (2000) Sperm binding capacity and ultrastructure of the zona pellucida of stored canine oocytes. J Reprod Fertil 119:77-83

Thaler CD, Cardullo RA (2002) Distinct membrane fractions from mouse sperm bind different zona pellucida glycoproteins. Biol Reprod 66:65-69

Vanroose G, Nauwynck H, Van Soom A et al (2000) Structural aspects of the zona pellucida of in vitro-produced bovine embryos: A scanning electron and confocal laser scanning microscopic study. Biol Reprod 62:463-469

Wassarman PM, Jovine L, Litscher ES (2001) A profile of fertilization in mammals. Nat Cell Biol 3:59-64

Wassarman PM, Jovine L, Litscher ES (2004) Mouse zona pellucida genes and glycoproteins. Cytogenet Genome Res 105:228-234

Yanagimachi R (1994) Stability of the mammalian sperm nucleus. Zygote 2:383-384

Zhao M, Dean J (2002) The zona pellucida in folliculogenesis, fertilization and early development. Rev Endocr Metab Disord 3:19-26 